\title{
Risk stratification for diabetic eye screening
}

\author{
Irene M. Stratton • Steve J. Aldington
}

Received: 21 August 2013 / Accepted: 23 August 2013 /Published online: 22 September 2013

(C) Springer-Verlag Berlin Heidelberg 2013

\section{Abbreviation \\ EQA External quality assurance}

To the Editor: In the August issue of this journal Looker et al presented results from data analyses of patients from the Scottish Diabetic Retinopathy Screening programme [1]. The principal finding was that transition rates to referable diabetic eye disease were lowest among people with type 2 diabetes and who had had two consecutive screens showing no visible retinopathy. We had already published this result in Diabetes Care [2], online in November 2012 and in print in March 2013 but this has not been acknowledged by Looker et al. We recognise that our results were based on data from patients for whom we had no information on the type of diabetes, but they would predominantly have been patients with type 2 diabetes because they were from a populationbased screening programme in England. The transition rates found in the Scottish study are of the same order as those found in our cohort.

The authors state that a major strength of the paper is that it uses a centralised quality-controlled grading system and the criteria for referable disease have not altered over the course of the programme. This tends to suggest a single reading centre although they have not expressly stated this. However, Goatman et al [3] reported in 2012 on external quality assurance (EQA) of grading in the Scottish programme in nine reading centres. They reported that there were significant differences in sensitivities and specificities between graders and between reading centres in 2008, when much of the data in the Looker paper would have been collected. This is not alluded to in the Looker paper [1].

\footnotetext{
I. M. Stratton $(\varangle) \cdot$ S. J. Aldington

Gloucestershire Diabetic Retinopathy Research Group, Gloucester Hospitals NHS Foundation Trust, Above Oakley Ward, Cheltenham General Hospital, Sandford Road, Cheltenham, Gloucestershire GL53 7AN, UK

e-mail: irene.stratton@nhs.net
}

The authors discuss several possible reasons for the apparent regression of mild background retinopathy to no visible retinopathy at subsequent examination. However, they do not raise the possibility that this may be due to changes in grading or the differences in sensitivity and specificity between graders enumerated in the EQA paper [3].

These recent results suggest that a 2 year screening interval may be safe in those with type 2 diabetes and no visible retinopathy on two consecutive screens. In our paper [2] this may be deduced from the results. However we also discuss the quality of our grading and the need to validate these results in other populations before implementation of changes in screening intervals. There is no 'gold standard' for grading of digital retinal images and hence the introduction of extended intervals in any programme would require validation of any rules in existing datasets, continuing education of graders and robust failsafe procedures, EQA and QA of grading.

Funding This work received no specific grant from any funding agency in the public, commercial or not-for-profit sectors.

Duality of interest The authors declare that there is no duality of interest associated with this manuscript.

Contribution statement Both authors were responsible for the conception and design of the manuscript, drafting the article and revising it critically for important intellectual content. Both authors approved the version to be published.

\section{References}

1. Looker HC, Nyangoma SO, Cromie DT et al (2013) Predicted impact of extending the screening interval for diabetic retinopathy: the Scottish Diabetic Retinopathy Screening programme. Diabetologia 56: $1716-1725$

2. Stratton IM, Aldington SJ, Taylor DJ et al (2013) A simple risk stratification for time to development of sight-threatening diabetic retinopathy. Diabetes Care 36:580-585

3. Goatman KA, Philip S, Fleming AD et al (2012) External quality assurance for image grading in the Scottish Diabetic Retinopathy Screening Programme. Diabet Med 29:776-783 